\title{
Uma visão indígena da história
}

\author{
Paulo Humberto Porto Borges*
}

\begin{abstract}
RESUMO: Este artigo tem como objetivo discutir as possibilidades de ensino e construção de conhecimentos históricos na comunidade indígena guarani-mbya, da aldeia de Sapucaí, em um contexto de educação escolar intercultural. Refletindo acerca da utilização de documentação imagética - fotografias, gravuras e iconografias produzidas por não-índios como fontes históricas na reconstrução e no registro de uma memória indígena.
\end{abstract}

Precisamos da história, mas não como precisam dela os ociosos que passeiam no jardim da ciência.

(Nietzsche, F.

"Vantagens e desvantagens da história para a vida") ${ }^{1}$

Por onde começar a discussão sobre este tema inexplorado por educadores, antropólogos e completamente ignorado por historiadores? Como apresentar propostas de ensino de história considerando a diversidade situada entre dois interlocutores? De um lado, a cultura dominante, com sua concepção de história sedimentada, e, do lado oposto, os grupos dominados, com registros e referenciais próprios. Como enfrentar a situação desafiante de propor formas educacionais para o ensino de história respeitando as diferenças culturais e históricas dos dois grupos? (Bittencourt 1994)

* Doutorando e professor da Faculdade de Educação da Unicamp e membro do Núcleo de Cultura e Educação Indígena da ALB (Associação de Leitura do Brasil). Home page: www.djweb.com.br/historia. 
Foi com todas essas indagações e mais algumas que, em março de 1997, aceitei o convite feito pelos educadores da escola indígena guarani Kyringue Yvotyty da aldeia de Sapucaí ${ }^{2}$ para assessorá-los na prática e no ensino de história, visando a uma educação escolar intercultural.

Os educadores guarani, de forma geral, argumentavam que gostariam de "ensinar a verdadeira história guarani, a história dos antigos", em contraposição à história narrada e confirmada pelos mais diversos livros didáticos que lhes caíam nas mãos. Nestes, no mais das vezes, pouca ou nenhuma referência se fazia à temática indígena, e, quando havia alguma, freqüentemente não era muito específica e sequer se fazia a tão necessária diferenciação entre os povos indígenas do Brasil, caracterizando os mais de 200 povos, cada qual com sua tradição e seus costumes, referindo-os apenas como índios.

É preciso ter claro que quando os educadores indígenas afirmam que gostariam de uma "história bem ensinada", eles estão se referindo a uma história que reforce e reconheça um projeto étnico-cultural. Não podemos esquecer que o ensino e o trato com a história sempre estiveram intimamente ligados com a identidade de um povo. Segundo o historiador Marc Ferro, a função do saber histórico e do historiador é "contribuir para a inteligibilidade do passado, dos vínculos entre o passado e o presente" (1989, p. 108), o que, sem dúvida, termina por construir e consolidar o ethos de um determinado grupo. Entretanto, o mesmo Marc Ferro indaga: “...terão os acontecimentos históricos a mesma significação para todos? Sua lição será a mesma para todos? Assim, a batalha de Poitiers, apresentada como um acontecimento feliz na história nacional francesa, não o é para a historiografia árabe" (idem, ibid.). E parodiando Marc Ferro, poderíamos afirmar que assim como a conquista da América é vista como um acontecimento feliz na história ocidental, muito provavelmente não o é para uma possível historiografia indígena.

Sem dúvida, a busca dos educadores indígenas de Sapucaí por uma história bem ensinada perpassa por todas essas questões, pois apenas uma história que realmente represente a visão de mundo de um povo é que poderá ser significativa na constituição de sua identidade.

Um exemplo interessante dessas histórias diferenciadas pode ser observado na origem histórica da rabeca, ou ravé - violino rudimentar originário das antigas missões jesuíticas e ainda hoje fabricado e utilizado pelos índios em suas danças e rezas tradicionais. Segundo os 
guarani, a rabeca, longe de ser um instrumento trazido pelos jesuítas europeus, seria uma invenção dos índios e, ainda segundo eles, "depois é que os brancos imitaram e aperfeiçoaram no violino". ${ }^{3}$ Duas vertentes, duas visões, dois percursos desdobram-se diante de nossos olhos com todas as suas continuidades. Diante dessa disputa, qual história deve ser apreendida? Qual versão deve ser privilegiada: a história elaborada pelo grupo, resultado da persistência de valores tribais, ou a chamada "história dessacralizada", pautada em farta documentação colonial ${ }^{4}$

Como nas palavras de Bartomeu Melià, ao comentar a confecção de livros didáticos de história para comunidades guarani em terras paraguaias:

Porque nos dois primeiros volumes não tratavam destas coisas, mas chega o momento em que eles também têm de falar da "história real". A esses povos, falamos ou não falamos da antropofagia em seus livros? Esse é outro problema muito grande. Falamos ou não falamos de suas guerras? ${ }^{5}$

Além da discussão em relação a qual perspectiva histórica deve ser privilegiada - que, em última instância, deve ser sempre o referencial histórico do grupo envolvido -, alguns outros problemas impõem-se quando pensamos em ensino de história para povos que não possuem a escrita como principal tradição documental. Ou mesmo, como trabalhar o ensino de história sem ameaçar a velha tradição oral e seus grandes narradores: os sacerdotes da palavra, os mais idosos do grupo, que, por sua vivência acumulada, ainda possuem a magnífica função de resguardar a memória de seu povo.

Escrever os relatos dos mais velhos sobre o passado da aldeia, de seus mitos, de suas festas, poderá levar a quais tipos de conflitos entre o próprio grupo, e como serão estabelecidas as novas relações entre o saber histórico tradicionalmente transmitido e o saber histórico desenvolvido pela cultura escolar?" (Bittencourt 1994, p. 113)

Ainda nesse sentido, uma possível historicização do mito, ou das diversas mitologias de um determinado grupo, é uma forma bastante ar- 
riscada de buscar um relato histórico. A mitologia de um povo não deve ser tratada no âmbito escolar, e sim no espaço usual e já consagrado pela tradição: o espaço cultural, familiar e religioso. Qualquer tentativa de confinar o mito em livros didáticos de história pode nos conduzir a um perigoso descompasso cultural. Ao contrário do que pode parecer, a grafia e o registro da mitologia de um povo não significam sua valorização ou mesmo sua preservação.

\begin{abstract}
Um povo que um dia opta por escrever seus mitos, as belas palavras de suas origens - palavras originais -, não estará provavelmente em melhores condições de tê-los sempre presentes na memória do que nos tempos em que os mitos eram palavra recriada nas circunstâncias mais ordinárias da vida. Há inclusive indícios de que o povo sente sua morte próxima, ao menos a morte do modo de vida originado no mito; a morte da palavra em que se dizem suas origens como memória de futuro. O mito, quando não é falado, deixa na realidade de ser mito; volta a sê-lo quando entra de novo na palavra viva de uma comunidade (...), no momento, seria muito perigoso verter o discurso religioso guarani nos moldes da escrita. (Melià 1997, p. 104)
\end{abstract}

Segundo os educadores indígenas da Escola Kyringue Yvotyty, o ensino de história a ser ministrado em sala de aula deveria abarcar a história do povo guarani e a história dos povos indígenas em seu conjunto. No entanto, além dos chamados "documentos oficiais" produzidos pelos povos conquistadores, existem poucas evidências materiais deixadas pelas populações autóctones da América portuguesa. O que nos dá poucas possibilidades de, com o auxílio dessa documentação que são os relatos do ponto de vista europeu, construir uma visão que contemple a perspectiva dos povos indígenas - no caso, o grupo guarani. É necessário promover o diálogo entre essas diversas versões, entre a memória guarani e a extensa documentação produzida a respeito de seu povo. Porém, não se trata de contrapor e confrontar uma documentação com outra, a fim de arrancar a verdade como se arranca uma confissão, mas de uma aposta num possível intercâmbio. Um intercâmbio que não acontece com a facilidade de uma conversa entre amigos à mesa de um café, mas como a conversa tensa de veIhos conhecidos que precisam acertar antigas diferenças.

Em nosso diálogo entre uma visão indígena e uma documentação não-índia, terminamos por eleger dois interlocutores privilegiados: a me- 
mória histórica da comunidade guarani, perpetuada por uma forte tradição oral, e, dentre as várias fontes não-índias à disposição, imagens na forma de gravuras, pinturas e fotografias construídas por viajantes, antropólogos e fotógrafos oficiais do antigo Serviço de Proteção ao Índio (SPI) sobre os guarani e outros povos indígenas.

A opção de trabalhar com um grande número de documentos imagéticos deveu-se basicamente a dois motivos:

a) a dificuldade que alguns professores e lideranças guarani possuem em relação ao domínio dos códigos de leitura e escrita, limitando consideravelmente sua compreensão de documentos escritos;

b) o caráter polissêmico e aberto da imagem permite diversas leituras de acordo com a perspectiva histórica do sujeito. Nesse sentido, a imagem, em nosso trabalho, é bem mais do que apenas "uma saída" para a dificuldade de utilizar documentos escritos - trata-se de um poderoso instrumento que permite aflorar aspectos da "perspectiva histórica do sujeito", no caso, os educadores guarani de Sapucaí, que dificilmente viriam à tona de outra forma.

A primeira referência quanto às imagens utilizadas aqui é o acervo fotográfico do Museu do Índio, do qual, com a ajuda dos professores indígenas da Escola Kyringue Yvotyty Celso Verá Mirim e Renato da Silva, foram selecionadas todas as fotografias que retratassem o povo guarani, fossem kaiowá, ñandeva ou mbya ${ }^{6}$ (apesar de estarmos mais preocupados em encontrar imagens sobre os guarani-mbyas), compreendendo o período de 1890 a 1994. Ainda ao Museu do Índio deveu-se o acesso a relatórios de antigas inspetorias do SPI, em especial os da Quarta e Quinta Delegacias Regionais, no período de 1920-1960, ${ }^{7}$ e alguns artigos de jornais sobre os guarani, como o do jornal $A$ Batalha de $1 / 3 / 1931$, que nessa data entrevistou uma liderança guarani-kaiowá sobre supostos "desmandos" do SPI em São Paulo. Ao todo, entre fotografias, relatórios e artigos de jornais, foram selecionados 685 documentos (640 fotografias, 41 relatórios e 4 artigos).

Como documentação imagética também foram utilizadas as pinturas de J.B. Debret, as xilogravuras das viagens de Hans Staden (de autor desconhecido) e o filme The mission, de Roland Joffé. ${ }^{8}$ Ao contrário do filme, que é centrado exclusivamente sobre a história dos guarani, a maioria das imagens de Debret e a totalidade das xilogravuras em Hans Staden tratam de outros grupos indígenas, como os botucudo e os tupinambá. Entretanto, ainda assim, optei por trabalhar com essas ima- 
gens por tratarem de grupos que viveram na região do Rio de Janeiro, atual morada dos guarani de Sapucaí (além de os tupinambá pertencerem ao mesmo tronco lingüístico dos guaraní), o que, de certa forma, garantiu uma identidade dos guarani em relação a tais registros.

Essa proposta de trabalho, em que gravuras e fotografias aparecem com status de documentos, ao contrário do que pode parecer, não causou tanta surpresa nos educadores indígenas da comunidade guarani de Sapucaí, pois a utilização da máquina fotográfica como produtora de registros históricos não é estranha, ou nova, para as comunidades indígenas de maior contato com a sociedade não-índia. Já há algum tempo, os guarani perceberam a importância documental que a maioria dos não-índios dá para o registro fotográfico e para o vídeo, ${ }^{9}$ a ponto de o cacique de Sapucaí, João da Silva, incluí-lo, de maneira sintomáti$\mathrm{ca}$, em seu relato acerca do descobrimento do Brasil:

\begin{abstract}
Vovô me contava histórias do que aconteceu sobre o primeiro que descobriu o Brasil, o Pedro Cabral. Não sei ao certo, diz que naquele tempo nós índios nem conhecíamos o branco. Então diz que um dia apareceu um barco grande que vinha chegando. $O$ índio sentiu medo, pensou que fosse bicho e atirou com flecha, naquele tempo o guarani tinha flecha. Flecha não faz nada, bate e voa por cima do barco, que quando encostou na praia, aí saiu gente. Então o índio conheceu o branco. O índio atirou porque nunca tinha visto antes aquilo, mas quando viu o branco sair do barco, aí parou. Então os outros chegaram, viram índio e bateram foto. (Litaif 1996, p. 136)
\end{abstract}

Segundo a interpretação do cacique João da Silva, sem a presença de um fotógrafo, ou da fotografia, a chegada de Pedro Cabral ficaria menos documentada. Talvez seu João não concebesse um juruá ${ }^{10}$ que, ao seu primeiro encontro com índios, resistisse a tirar ao menos uma foto.

\title{
Oficinas de história
}

O trabalho de metodologia e ensino de história com os professores guarani da escola indígena Kyringue Yvotyty foi organizado, além de assessorias mensais, ${ }^{11}$ em duas oficinas com a participação de várias 
lideranças e educadores indígenas. Na primeira, desenvolvemos uma "Oficina de História" com os professores de Sapucaí durante três dias, na qual discutimos conceitos de história e elaboração de documentos. O trabalho foi desenvolvido na escola da comunidade e contou com a participação ativa - isto é, na discussão e na produção de material - de aproximadamente 19 indígenas, entre educadores e lideranças da comunidade, contando ainda com uma população flutuante de mais de dez pessoas - que apareciam, ficavam algumas horas, participavam de alguns grupos e, por fim, partiam novamente. Ao todo, a oficina envolveu cerca de 30 guaranis (direta e indiretamente). Como material documental utilizamos diversos livros e autores sobre os guarani, como Nimuendaju, Cadogan e Melià.

Também trabalhamos com diversas documentações produzidas sobre os povos indígenas, especialmente documentos visuais - como as gravuras encontradas no livro de Hans Staden (século XVI) e as pinturas de Debret (século XIV), além das várias fotografias produzidas pelo Comissão Rondon e pelo antigo SPI (século XX). ${ }^{12}$

Essas imagens (aproximadamente 150 fotocópias de 50 imagens), ${ }^{13}$ após serem apresentadas quanto a sua datação e autoria, foram dispostas em uma mesa, e os participantes foram convidados a "continuar a história" sugerida ou narrada pela imagem que eles escolhessem. Ao final da escolha, cada qual, com a devida ajuda daqueles que escreviam em guarani ou em português, elaborava seu texto. Depois de elaborados os textos, os autores, um por vez, apresentavam sua produção para os demais guaranis.

Ao final, o filme The mission, ${ }^{14}$ do diretor Roland Joffé, foi exibido para uma platéia de 17 guaranis (houve uma pequena redução no número de participantes em virtude de nosso deslocamento forçado para a cidade de Angra dos Reis, distante 20 quilômetros - meia hora de ônibus). ${ }^{15}$

Após a exibição (que durou cerca de três horas, pois, como o filme era legendado e nem todos liam em português, paramos em algumas cenas para que os educadores guarani pudessem dar explicações na língua guarani; entretanto, apesar dessas dificuldades - como o longo tempo de duração e a legenda -, os 17 guaranis assistiram ao filme com um interesse comovido), discutimos sobre os Sete Povos de Missões e os chamados índios missioneros.

Uma segunda oficina foi promovida no I Encontro de Educadores Guarani dos Estados do Rio de Janeiro e de São Paulo, que ocorreu na primeira semana de agosto de 1997 em Angra dos Reis, quando tra- 
balhamos durante dois dias com professores indígenas de diversas aldeias guarani desses dois estados.

Nessas duas oficinas desenvolvemos basicamente os mesmos conceitos, com algumas variações em relação à metodologia, que fluiu mais à vontade na segunda oficina, justamente por alguns professores já estarem familiarizados com a proposta e a dinâmica de trabalho. ${ }^{16}$

Durante as oficinas trabalhamos com um amplo leque documental, sempre privilegiando, em virtude da barreira lingüística, uma documentação imagética, como filmes, slides, gravuras, fotografias e pinturas elaboradas e produzidas por viajantes, pesquisadores e agentes oficiais acerca das populações indígenas do litoral paulista e carioca. Com base nessas imagens, os educadores guarani produziram textos em guarani ou em português.

A utilização da imagem como fonte documental acabou induzindo a uma narrativa que talvez não viesse à tona de outro modo, permitindo o afloramento de fragmentos dessa mesma história, despertando no leitor a vontade de dar continuidade à narrativa sugerida pela imagem, como se a imagem tivesse o poder de fragmentar e isolar um determinado reflexo da historicidade coletiva, tornando-o mais visível e facilitando sua análise e apreensão.

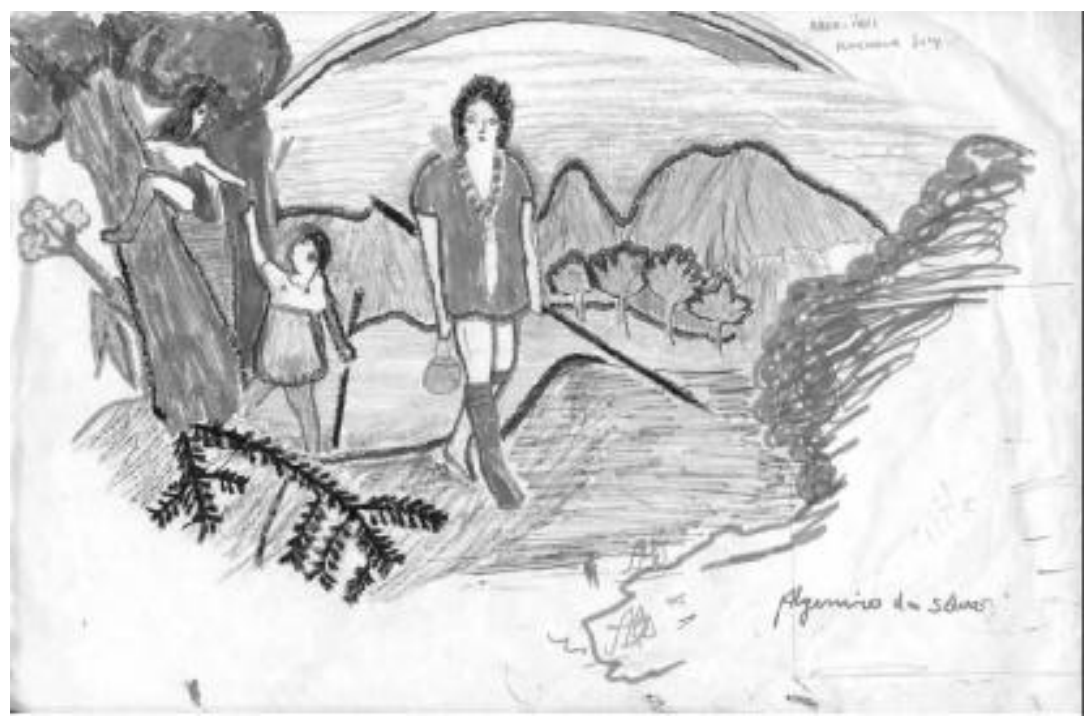


Walter Benjamin já nos indicava a visibilidade dada pela fotografia às criações individuais por destacá-las da grande criação coletiva:

Cada um de nós pode observar que uma imagem, uma escultura e principalmente um edifício são mais facilmente visíveis na fotografia do que na realidade. A tentação é grande de atribuir a responsabilidade por esse fenômeno à decadência do gosto artístico ou ao fracasso dos nossos contemporâneos. Porém, somos forçados a reconhecer que a concepção das grandes obras se modificou simultaneamente com o aperfeiçoamento das técnicas de reprodução. Não podemos agora vê-las como criações individuais; elas se transformaram em criações coletivas tão possantes que precisamos diminuí-las para que nos apoderemos delas. Em última instância, os métodos de reprodução mecânica constituem uma técnica de miniaturização e ajudam o homem a assegurar sobre as obras um grau de domínio sem o qual elas não mais poderiam ser utilizadas. (Benjamin 1996, p. 104)

Nesse sentido, durante as Oficinas de História com os guarani a imagem mostrou-se um instrumento privilegiado de apropriação da realidade, ou melhor, de um determinado fragmento da realidade, permitindo um grau de domínio da memória que, sem a imagem, iria provavelmente se perder na infinitude da criação coletiva. Assim como Benjamin fala em miniaturizar esculturas e edifícios, situados no campo das grandes obras, a fim de permitir sua apropriação, buscamos por meio de documentos visuais destacar estilhaços pertencentes à memória coletiva, possibilitando um momentâneo domínio acerca desses fragmentos.

Esse trabalho ${ }^{17}$ terminou por produzir um Caderno de História, denominado pelos educadores guarani de Nhaneretarã Kuery Va'e Kuery Nhanemãndu'aa, ${ }^{18}$ que foi editado com o auxílio financeiro do MEC e entidades não-governamentais e que, atualmente, vem sendo utilizado pelos professores guarani da Escola Kyringue Yvovtyty.

O conjunto dos educadores guarani optou pela elaboração de uma versão monolíngüe (guarani) do Caderno de História, com a argumentação de, dessa forma, estar estimulando a leitura na língua materna e, conseqüentemente, confeccionando material para o aprendizado da língua guarani. ${ }^{19}$ Por essa razão, decidiu-se reafirmar a língua indígena em detrimento da língua portuguesa - que, em última instância, é a língua do colonizador - na produção do caderno. Mes- 
mo porque a edição visava apenas às comunidades guarani e seus respectivos processos escolares, e não havia a necessidade de produzir material didático bilíngüe (português-guarani) se a proposta do ensino formal de português na escola de Sapucaí acontece apenas no quarto ciclo, ou seja, a partir dos 12 anos. Dentro dessa perspectiva, caso se optasse pela edição bilíngüe, seria apenas para satisfazer a curiosidade de leitores não-índios ou uma simples questão de marketing. O que realmente não era nosso caso.

Em sua maioria os textos enfatizaram a história da conquista, registrando o que seria uma visão indígena dos 500 anos da América e o trauma da chegada dos europeus. Como no relato do guarani Valdo Rodrigues da Silva ao interpretar, à sua maneira, a clássica prancha de Debret Soldados índios de Curitiba escoltando selvagens.

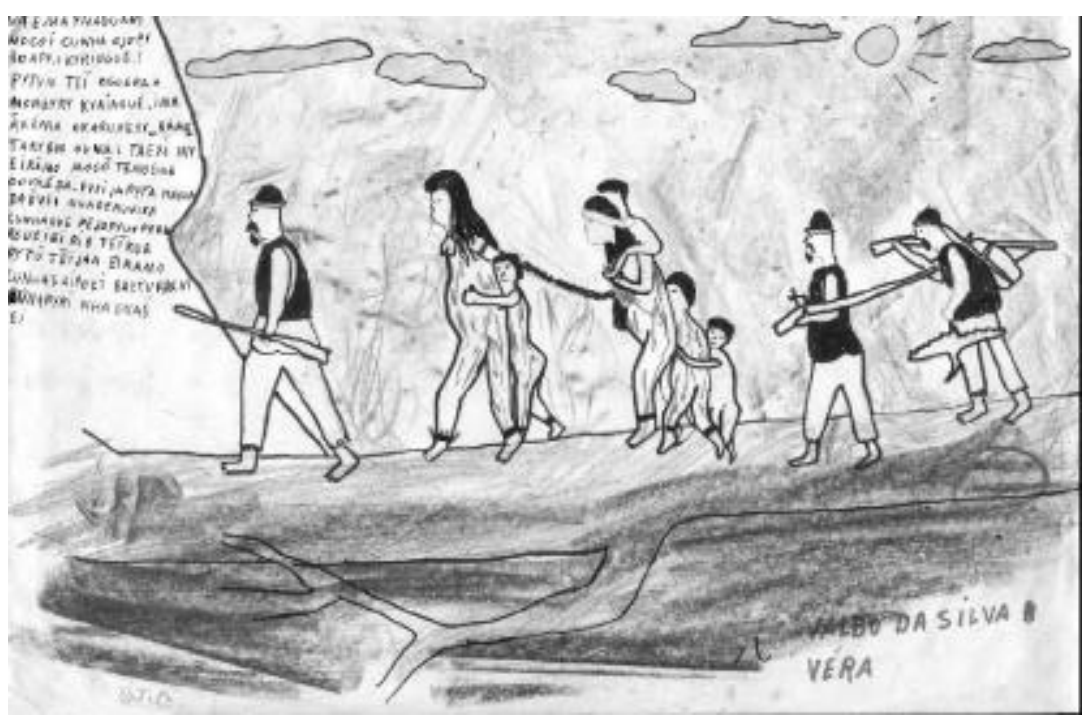

Imagem de Debret: Releitura

Mokoi kunha, ha'e irundy kyringue'i.

Pytu tei ogueraa tema mombyry, omoxã eravy.

Kyringue'i haxe ma okaruxevy tei, jurua kuery ndoikuaaxei.

Ha'eramo ixy kuery aipoe'i: 
- Jajaru rive rãema!

- Nhandekuery aema Nhanderuvixa nhanemonguetaa nanhaendui vyma kova'e rã py nhavae. ${ }^{20}$

Ou mesmo na reelaboração do professor guarani Renato da Silva em relação à possível antropofagia dos povos indígenas ao refletir sobre as xilogravuras e os textos presentes no livro Duas viagens ao Brasil de Hans Staden.

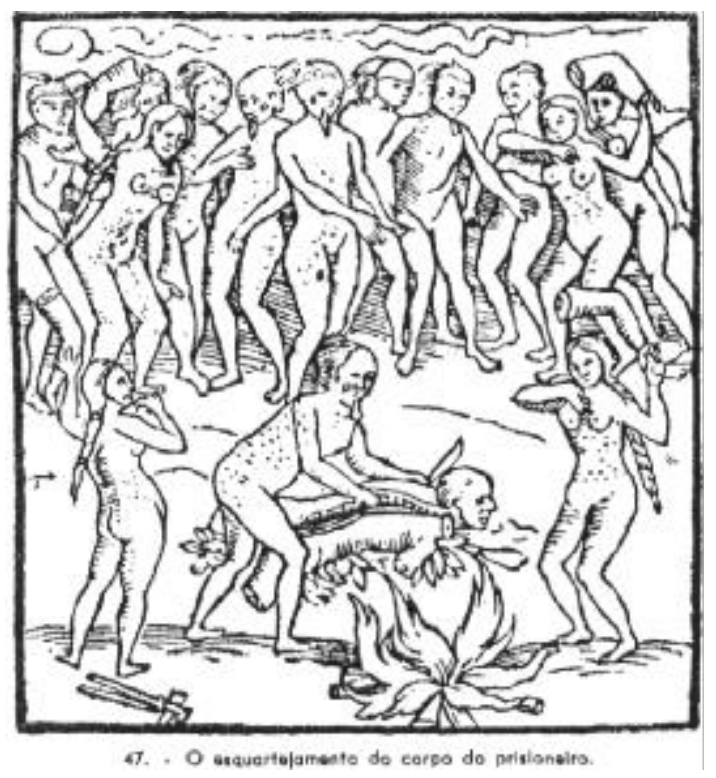

Imagem da xilogravura de Hans Staden

Nhane'rentãra kuery ma hetava'e kuery oikuaa ramo mba'emo rive merãmi ha'e kuery ma ijayu nhande kuery jajo'u va'e arami oikuaa. Va'eri ha'eva'e anhetegua'ey orema roikuaa'avei amboae juery. Etava'e kuery voi ore kuery roikova'e ka'aguy mbytere aeva'e roikuaa kova'e. O Hans Staden ma petei etava'eregua Portugal regua ou opyta raka'e mbya kuery mbytepy oiko porã nhombyte rupi mbya kuery onhanga reko porã raka'e.

Ha'e omombe'u rãngue jajexavaia va'eri ha'e anho onhemo arandu vexevy ijayu parei rive omombe'u anhetengua he'y. 
Ore kuery ma orerekoa ripi amongue va'e imba'e ha'xiramo rojepy apyma exe pytu maramo yvyra'ija onhanga reko ogueraa jepe anguã.

Ore rekoma kova'erupi. ${ }^{21}$

Essas veredas e distintas interpretações históricas produzidas pelos professores guarani em busca de uma "história bem ensinada" 22 - mas não no sentido de uma "história verdadeira", e sim em relação a uma história pautada na tradição e na memória guarani - vêm apontando para um ensino de história específico na Escola Kyringue Yvotyty. ${ }^{23}$

\section{Notas}

1. Nietzsche apud Benjamin 1996, p. 228.

2. Comunidade indígena guarani situada no município de Angra dos Reis/RJ.

3. Gravação-depoimento de Manuel Werá em 11/2/95.

4. Toda documentação escrita produzida pelos numerosos pesquisadores e historiadores (como jesuítas e viajantes) acerca dessas populações.

5. Palestra proferida pelo professor Bartomeu Melià em março de 1994 na cidade de El Dourado/Argentina.

6. Subgrupos do povo guarani.

7. Essas duas delegacias praticamente cobriam todos os aldeamentos guarani, que iam do litoral do Rio Grande do Sul ao litoral paulista, além da região compreendida pelo atual Mato Grosso do Sul.

8. The mission. Inglaterra, 1986 - duração 125 min.

9. Em maio de 1995 produzi um vídeo, a pedido da comunidade guarani de Rio Branco/SP, a fim de registrar o txondaro (dança típica guarani) para "guardar para os mais novos".

10. Termo que os guarani utilizam para designar o não-índio.

11. O trabalho com a comunidade iniciou-se em fevereiro de 1997 e encontrase em andamento.

12. Sempre privilegiando fontes documentais relacionadas aos guarani ou aos antigos carijó (grupo indígena pertencente à "grande nação guarani" que habitava os atuais estados de São Paulo e Paraná). 
13. Optou-se por trabalhar com cerca de três cópias de cada original a fim de evitar que algum participante ficasse sem a sua "imagem favorita" - e, dessa forma, fosse forçado a escolher uma outra - porque esta já havia sido escolhida anteriormente. Ou seja, para garantir que até duas pessoas pudessem escolher o mesmo documento.

14. A idéia original era apresentar o filme antes da iniciar a produção dos textos, como forma de subsidiar documentalmente os participantes da Oficina. Porém, em decorrência de problemas de infra-estrutura, acabamos por inverter o processo.

15. Atualmente na aldeia de Sapucaí não há energia elétrica, daí a impossibilidade de exibirmos o vídeo na escola indígena.

16. A primeira oficina aconteceu na aldeia de Sapucaí em meados de julho, contando apenas com professores indígenas da escola guarani Kyringue Yvotyty. A segunda oficina ocorreu no município de Angra dos Reis em fins de agosto e contou com a participação de 20 professores guarani de seis comunidades do Rio de Janeiro e de São Paulo.

17. Esses workshops aconteceram nos dias 30 de junho, 1 e 2 de julho (apenas com a participação de professores e lideranças da comunidade de Sapucaí) e de 23 a 31 de agosto de 1997 (com a presença de outras assessorias, como a de alfabetização bilíngüe e legislação indígena, e com a presença de 32 professores guarani oriundos de comunidades do Rio de Janeiro e de São Paulo).

18. Nossa gente, nosso passado, nossa memória.

19. Bartomeu Melià não se cansa de alertar para a dificuldade de se criarem leitores indígenas em um mundo sem literatura indígena. Não se pode incentivar a alfabetização da língua guarani se não existem livros em guarani.

20. "São duas mulheres presas carregando cinco crianças que estão chorando de fome, e mais dois soldados que estão acompanhando. Elas estão presas. Elas conversam:

- Puxa, a gente devia ter ouvido o cacique. Agora a gente está presa e nenhum parente nunca mais vai saber o que aconteceu com a gente.

- A gente está presa porque não ouviu o cacique."

21. "Nosso povo indígena é considerado como animais pelos portugueses. Falam que o índio come gente. Mas isso não é verdade. Nós, índios, também sabemos respeitar os outros povos indígenas e também o não-índio. Nós que vivemos anos e anos no meio da floresta sabemos disso. Hans Staden, um dos portugueses que foi parar na aldeia com os índios, ele foi bem tratado no meio dos índios. Ele podia contar o sofrimento dos índios, mas ele quis ser famoso, inventando tudo mentira. Nós índios quando tem alguma 
pessoa doente na aldeia a gente fica se preocupando por ele, a noite pajé fica rezando para salvar doente, nossa vida de índio é assim."

22. Como nas palavras iniciais do professor guarani Algemiro da Silva.

23. Deve-se ressaltar que esse trabalho de assessoria à aldeia de Sapucaí conta com o acompanhamento (tanto nas discussões como na realização das oficinas) do pedagogo Domingos Barros Nobre e da missionária Eunice Dias, que já vêm atuando como assessores na escola indígena guarani Kyringue Yvotyty desde 1995.

\section{An indigenous view of history}

ABSTRACT: The main goal of this article is to discuss the teaching possibilities and historical knowledge construction in the indigenous communities of Guarani-mbya, from Sapucaí Indian settlement, in an intellectual school education context. Thinking over about the use of image documentation - photography, pictures and iconography - not produced by indigenous people as historical sources in the reconstruction and recording of an indigenous memory.

\section{Bibliografia}

ABREU, Aurélio M.G. de. Culturas indígenas do Brasil. São Paulo: Traco, 1987.

BENJAMIN, Walter. Magia e técnica, arte e política. São Paulo: Brasiliense, 1996.

BITTENCOURT, Circe Maria Fernandes. "O ensino de história para populações indígenas”. Em Aberto $\mathrm{n}^{\circ} 63$ (Educação escolar indígena). Brasília: MEC, ano XIV, 1994, pp. 105-116.

CASTRO, Eduardo Viveiros de e CUNHA, Manuela Carneiro (orgs.). Amazônia. Etnologia e história indígena. São Paulo: NHII/USP/Fapesp, 1993.

CLASTRES, Pierre. A sociedade contra o Estado. Rio de Janeiro: Francisco Alves, 1978.

FERRO. Marc. A história vigiada. São Paulo: Martins Fontes, 1989.

LITAIF, Aldo. As divinas palavras: Identidade étnica dos guarani mbya. Florianópolis: Ed. da UFSC, 1996. 
MELIÀ, Bartomeu. "Bilingüismo e escrita". In: D'ANGELIS, Wilmar e VEIGA, Juracilda. (orgs.). Leitura e escrita em escolas indígenas. Campinas: ALB - Mercado de Letras, 1997, pp. 89-104.

RIBEIRO, Berta. O índio na história do Brasil. São Paulo: Global, 1987.

SILVA, Aracy Lopes da e GRUPIONI, Luís Donizete Benzi (orgs.). A temática indígena na escola. Brasília: MEC/Mari/Unesco, 1995. 